This copy is for your personal, non-commercial use only.

If you wish to distribute this article to others, you can order high-quality copies for your colleagues, clients, or customers by clicking here.

Permission to republish or repurpose articles or portions of articles can be obtained by following the guidelines here.

The following resources related to this article are available online at www.sciencemag.org (this information is current as of March 8, 2013 ):

Updated information and services, including high-resolution figures, can be found in the online version of this article at:

http://www.sciencemag.org/content/339/6124/1198.full.html

Supporting Online Material can be found at:

http://www.sciencemag.org/content/suppl/2013/03/07/339.6124.1198.DC1.html

This article cites 32 articles, 6 of which can be accessed free:

http://www.sciencemag.org/content/339/6124/1198.full.html\#ref-list-1

This article appears in the following subject collections:

Atmospheric Science

http://www.sciencemag.org/cgi/collection/atmos 


\section{A Reconstruction of Regional and Global Temperature for the Past 11,300 Years}

\author{
Shaun A. Marcott, ${ }^{1}$ Jeremy D. Shakun, ${ }^{2}$ Peter U. Clark, ${ }^{1}$ Alan C. Mix $^{1}$
}

Surface temperature reconstructions of the past 1500 years suggest that recent warming is unprecedented in that time. Here we provide a broader perspective by reconstructing regional and global temperature anomalies for the past 11,300 years from 73 globally distributed records. Early Holocene (10,000 to 5000 years ago) warmth is followed by $\sim 0.7^{\circ} \mathrm{C}$ cooling through the middle to late Holocene $(<5000$ years ago), culminating in the coolest temperatures of the Holocene during the Little Ice Age, about 200 years ago. This cooling is largely associated with $\sim 2^{\circ} \mathrm{C}$ change in the North Atlantic. Current global temperatures of the past decade have not yet exceeded peak interglacial values but are warmer than during $\sim 75 \%$ of the Holocene temperature history. Intergovernmental Panel on Climate Change model projections for 2100 exceed the full distribution of Holocene temperature under all plausible greenhouse gas emission scenarios.

$\mathrm{P}$ lacing present climate into a historical perspective beyond the instrumental record is important for distinguishing anthropogenic influences on climate from natural variability (1). Proxy-based temperature reconstructions of the past 1500 years suggest that the warming of the past few decades is unusual relative to preanthropogenic variations $(2,3)$, but whether recent warming is anomalous relative to variability over the entirety of the Holocene interglaciation (the past 11,500 years) (4) has yet to be established.

The 73 globally distributed temperature records used in our analysis are based on a variety of paleotemperature proxies and have sampling resolutions ranging from 20 to 500 years, with a median resolution of 120 years (5). We account for chronologic and proxy calibration uncertainties with a Monte Carlo-based randomization scheme (6). Our data set exhibits several important strengths, as well as limitations, as compared to global and hemispheric reconstructions of the past 1500 years $(2,3,7,8)$. For example, whereas reconstructions of the past millennium rapidly lose data coverage with age, our coverage increases with age (Fig. 1, G and H). Published reconstructions of the past millennium are largely based on tree rings and may underestimate lowfrequency (multicentury-to-millennial) variability because of uncertainty in detrending (9) [although progress is being made on this front (10)], whereas our lower-resolution records are well suited for reconstructing longer-term changes. Terrestrial records dominate reconstructions of the past millennium, whereas our stack is largely derived from marine archives $(\sim 80 \%)$. Unlike the reconstructions of the past millennium, our proxy data

${ }^{1}$ College of Earth, Ocean, and Atmospheric Sciences, Oregon State University, Corvallis, OR 97331, USA. ${ }^{2}$ Department of Earth and Planetary Sciences, Harvard University, Cambridge, MA 02138, USA.

*To whom correspondence should be addressed. E-mail: marcotts@science.oregonstate.edu are converted quantitatively to temperature before stacking, using independent core-top or laboratoryculture calibrations with no post-hoc adjustments in variability.

We took the $5^{\circ} \times 5^{\circ}$ area-weighted mean of the 73 records to develop a global temperature stack for the Holocene (referred to as the Standard ${ }_{5 \times 5}$ reconstruction) (Fig. 1, A and B). To compare our Standard ${ }_{5 \times 5}$ reconstruction with modern climatology, we aligned the stack's mean for the interval 510 to $1450 \mathrm{yr}$ B.P. (where yr B.P. is years before $1950 \mathrm{CE}$ ) with the same interval's mean of the global Climate Research Unit error-in-variables (CRU-EIV) composite temperature record (2), which is, in turn, referenced to the 1961-1990 $\mathrm{CE}$ instrumental mean (Fig. 1A). We then assessed the sensitivity of the temperature reconstruction to several averaging schemes, including an arithmetic mean of the data sets, a $30^{\circ} \times 30^{\circ}$ area-weighted mean, a $10^{\circ}$ latitudinal weighted mean, and a calculation of 1000 jackknifed stacks that randomly exclude $50 \%$ of the records in each realization (Fig. 1, C and D, and fig. S4). Although some differences exist at the centennial scale among the various methods (Fig. 1, C and D), they are small $\left(<0.2^{\circ} \mathrm{C}\right)$ for most of the reconstructions, well within the uncertainties of our Standard $\mathrm{S}_{5 \times 5}$ reconstruction, and do not affect the long-term trend in the reconstruction.

In addition to the previously mentioned averaging schemes, we also implemented the RegEM algorithm (11) to statistically infill data gaps in is particularly important over the past several centuries (Fig. 1G). Without filling data gaps, our Standard $_{5 \times 5}$ reconstruction (Fig. 1A) exhibits $0.6^{\circ} \mathrm{C}$ greater warming over the past $\sim 60 \mathrm{yr}$ B.P. (1890 to $1950 \mathrm{CE}$ ) than our equivalent infilled $5^{\circ} \times 5^{\circ}$ area-weighted mean stack (Fig. 1, C and D). However, considering the temporal resolution of our data set and the small number of records that cover this interval (Fig. 1G), this difference is probably not robust. Before this interval, the gaprecords not spanning the entire Holocene, which filled and unfilled methods of calculating the stacks are nearly identical (Fig. 1D).

Because the relatively low resolution and timeuncertainty of our data sets should generally suppress higher-frequency temperature variability, an important question is whether the Holocene stack adequately represents centennial- or millennialscale variability. We evaluated this question in two ways. First, we generated a single mean zero, unit variance white-noise time series and used it in place of our 73 records. The white-noise records were then perturbed through Monte Carlo simulations using the resolution and chronological uncertainty specific to each proxy record as well as a common $1{ }^{\circ} \mathrm{C}$ proxy uncertainty. We composited a Standard ${ }_{5 \times 5}$ global stack from these synthetic records and calculated the ratio between the variances of the stack and the input white noise as a function of frequency to derive a gain function. The results suggest that at longer periods, more variability is preserved, with essentially no variability preserved at periods shorter than 300 years, $\sim 50 \%$ preserved at 1000 -year periods, and nearly all of the variability preserved for periods longer than 2000 years (figs. S17 and S18). Second, spectral analysis indicates that the variance of the Holocene proxy stack approaches that of the global CRU-EIV reconstruction of the past 1500 years (2) at millennial time scales and longer (figs. S20 and S23).

Our global temperature reconstruction for the past 1500 years is indistinguishable within uncertainty from the Mann et al. (2) reconstruction; both reconstructions document a cooling trend from a warm interval ( $\sim 1500$ to $1000 \mathrm{yr}$ B.P.) to a cold interval ( $\sim 500$ to 100 yr B.P.), which is approximately equivalent to the Little Ice Age (Fig. 1A). This similarity confirms that published temperature reconstructions of the past two millennia capture long-term variability, despite their short time span $(3,12,13)$. Our median estimate of this long-term cooling trend is somewhat smaller than in Mann et al. (2) though, which may reflect our bias toward marine and lower-latitude records.

The Standard ${ }_{5 \times 5}$ reconstruction exhibits $\sim 0.6^{\circ} \mathrm{C}$ of warming from the early Holocene $(11,300 \mathrm{yr}$ B.P.) to a temperature plateau extending from 9500 to 5500 yr B.P.. This warm interval is followed by a long-term $0.7^{\circ} \mathrm{C}$ cooling from 5500 to $\sim 100$ yr B.P. (Fig. 1B). Extratropical Northern Hemisphere sites $\left(30^{\circ}\right.$ to $\left.90^{\circ} \mathrm{N}\right)$, in particular from the North Atlantic sector, contribute most of the variance to the global signal; temperatures in this region decrease by $\sim 2^{\circ} \mathrm{C}$ from 7000 yr B.P. to $\sim 100$ yr B.P. (Fig. $2 \mathrm{H}$ ). By comparison, the low latitudes $\left(30^{\circ} \mathrm{N}\right.$ to $\left.30^{\circ} \mathrm{S}\right)$ exhibit a slight warming of $\sim 0.4^{\circ} \mathrm{C}$ from 11,000 to $5000 \mathrm{yr}$ B.P., with temperature leveling off thereafter (Fig. 2I), whereas the extratropical Southern Hemisphere $\left(30^{\circ} \mathrm{S}\right.$ to $90^{\circ} \mathrm{S}$ ) cooled $\sim 0.4^{\circ} \mathrm{C}$ from about 11,000 to 7000 yr B.P., followed by relatively constant temperatures except for some possible strong multicentennial variability in the past 2500 years (Fig. $2 J)$. The Southern Hemisphere is represented by fewer data sets $(n=11)$ than the equatorial $(n=33)$ 
and Northern Hemisphere $(n=29)$ regions, providing fewer constraints on characterizing the variability in our reconstruction for this region.

Trends in regional temperature reconstructions show strong similarities with high-resolution pre- cipitation records, consistently associating greater warmth with greater wetness (Fig. 2, H to J). For example, extratropical Northern Hemisphere midto-high-latitude temperature correlates well with records of Asian monsoon intensity $(14,15)$ and the position of the Atlantic intertropical convergence zone (16) (Fig. 2H), tropical temperatures track precipitation proxies from speleothems in Borneo (17) and Indonesia (18) (Fig. 2I), and extratropical Southern Hemisphere temperatures parallel
Fig. 1. Comparison of different methods and reconstructions of global and hemispheric temperature anomalies. ( $A$ and B) Globally stacked temperature anomalies for the $5^{\circ} \times 5^{\circ}$ area-weighted mean calculation (purple line) with its $1 \sigma$ uncertainty (blue band) and Mann et al.'s global CRUEIV composite mean temperature (dark gray line) with their uncertainty (light gray band). (C and D) Global temperature anomalies stacked using several methods (Standard and Standard $_{5 \times 5 \text { Grid; 30x30Grid; } 10 \text {-lat: }}$ Arithmetic mean calculation, area-weighted with a $5^{\circ} \times$ $5^{\circ}$ grid, area-weighted with a $30^{\circ} \times 30^{\circ}$ grid, and area-weighted using $10^{\circ}$ latitude bins, respectively;

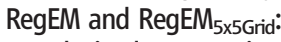
Regularized expectation maximization algorithminfilled arithmetic mean and $5^{\circ} \times 5^{\circ}$ area-weighted). The gray shading $[50 \%$ Jackknife ( Jack $\left._{50}\right)$ ] represents the $1 \sigma$ envelope when randomly leaving $50 \%$ of the records out during each Monte Carlo mean calculation. Uncertainties shown are $1 \sigma$ for each of the methods. (E and F) Published temperature anomaly reconstructions that have been smoothed with a 100-year centered running mean, Mann08 $8_{\text {Global }}(2)$, Mann08 $_{\mathrm{NH}}$ (2), Moberg05 (3), WA07 (8), Huange04 (36), and plotted with our global temperature stacks [blue band as in (A)]. The temperature anomalies for all the records are referenced to the 1961-1990 instrumental mean. (G and $\mathbf{H})$ Number of records used to construct the Holocene global temperature stack

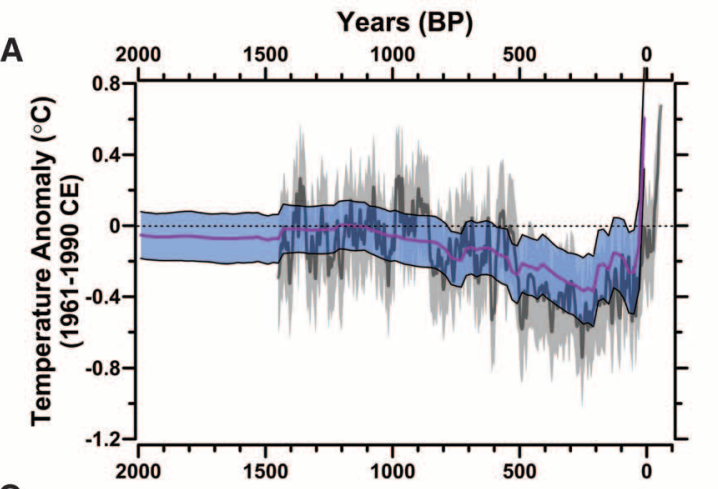

C

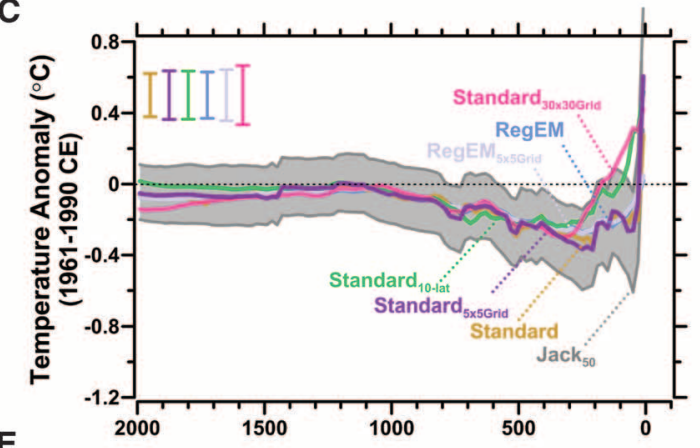

E

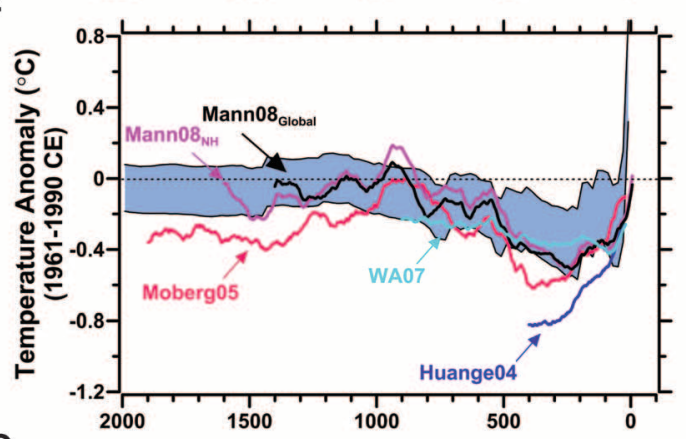

G
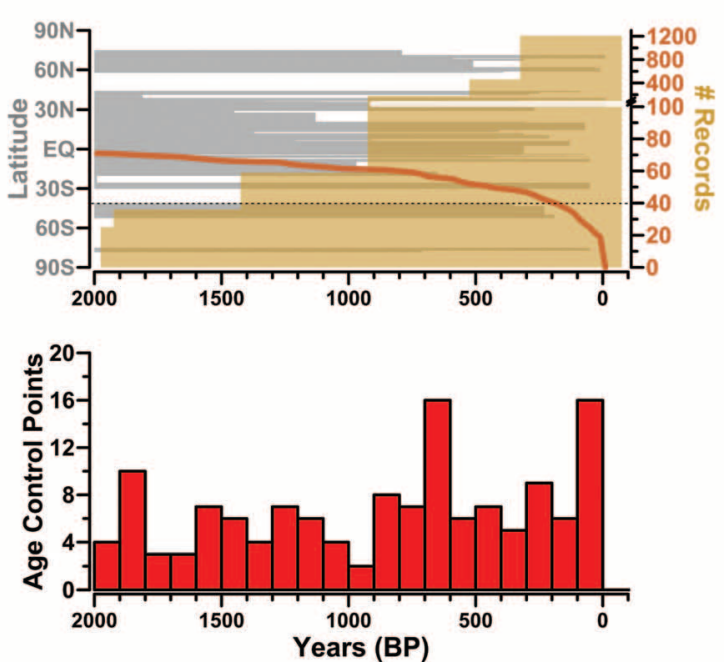

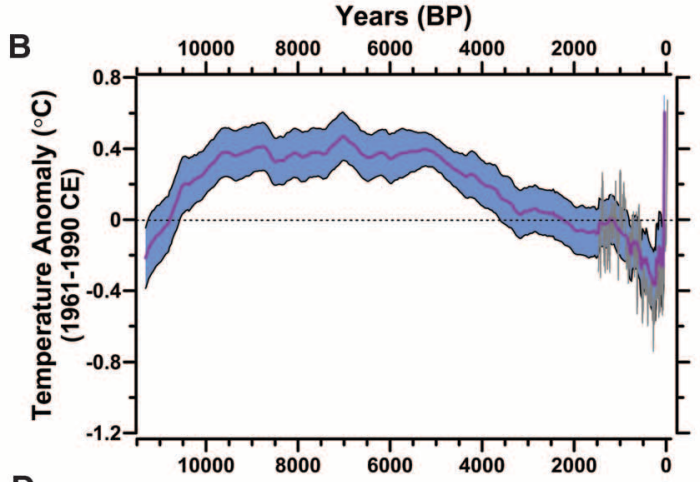

D

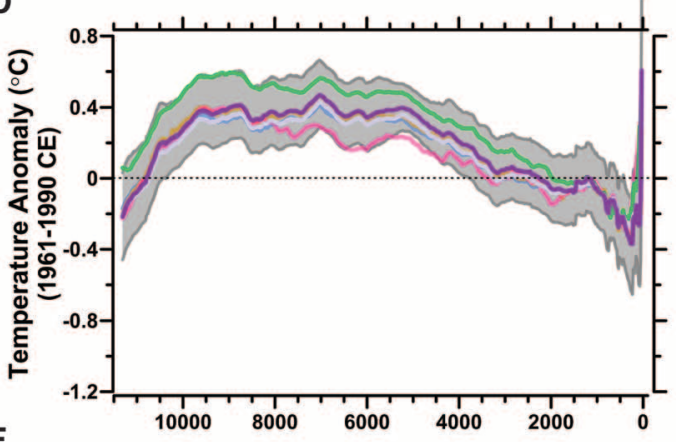

F
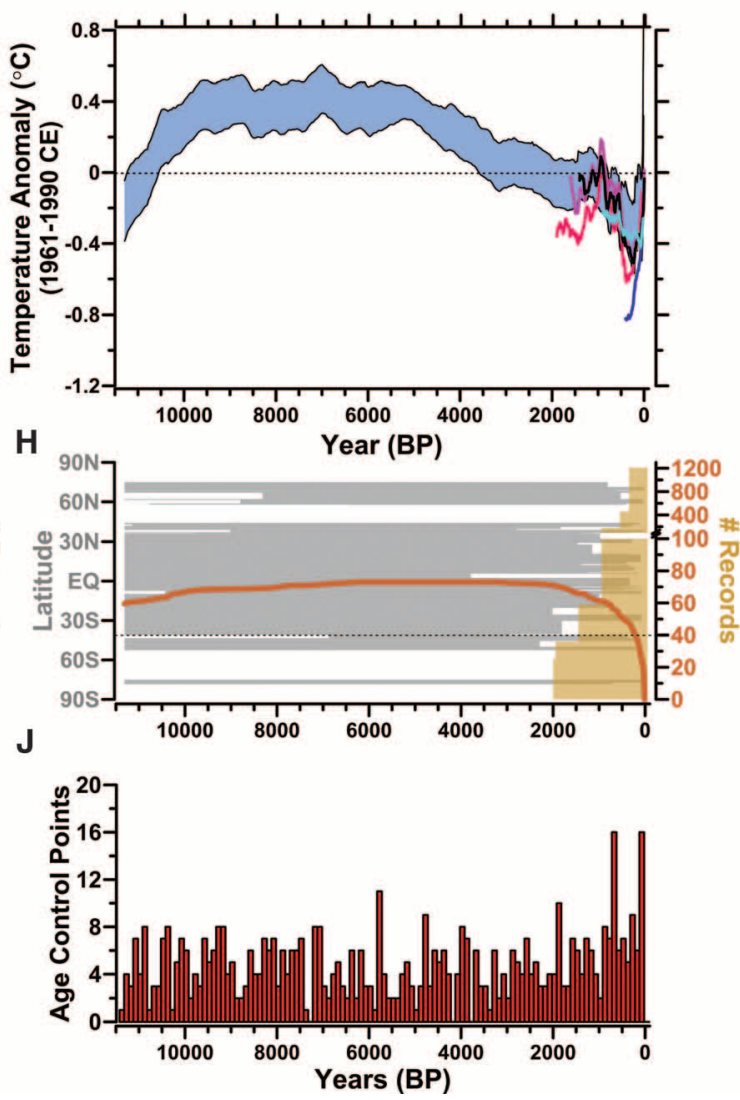

through time (orange line) and Mann et al.'s (2) reconstruction (gold vertical bars). Note the $y$ axis break at 100. The latitudinal distribution of Holocene records (gray horizontal bars) through time is shown. (I and J) Number of age control points (e.g., ${ }^{14} \mathrm{C}$ dates) that constrain the time series through time. 
A

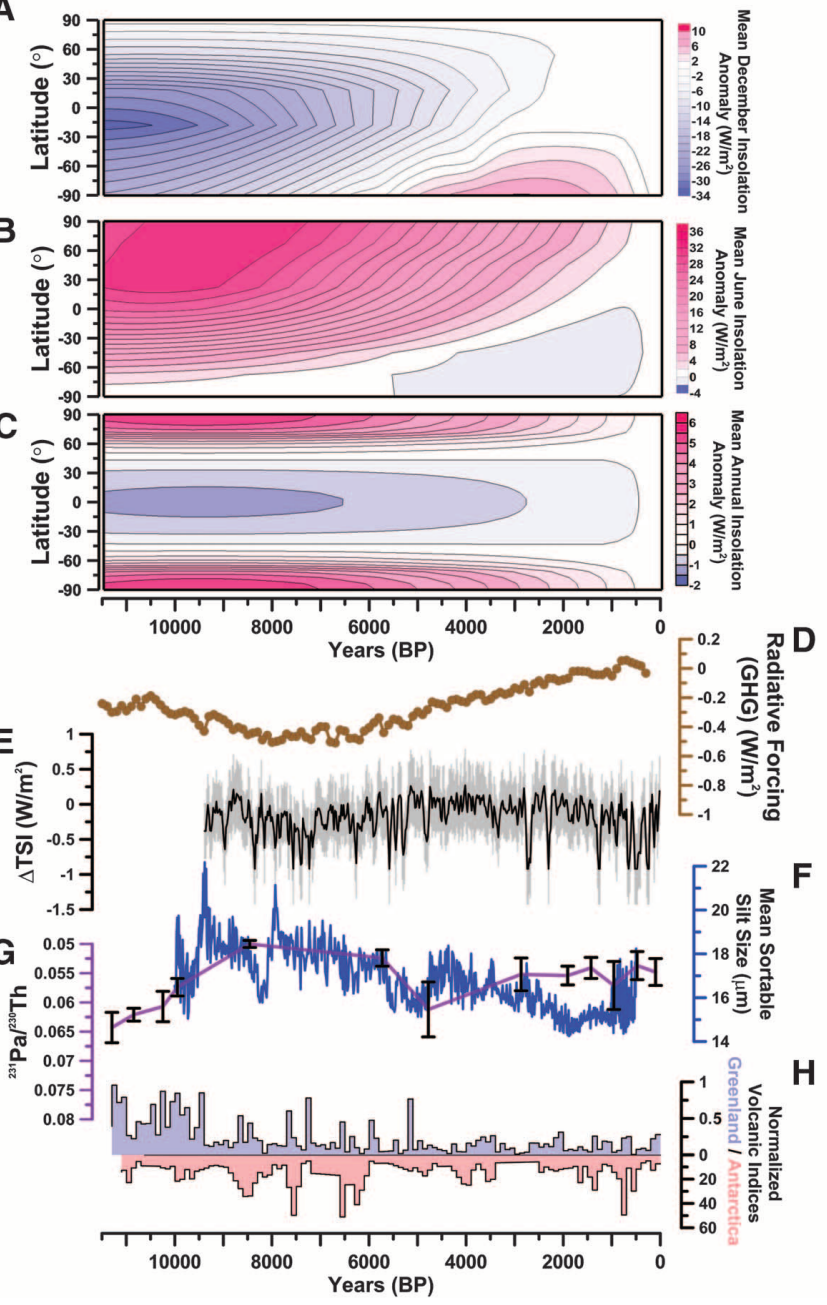

I
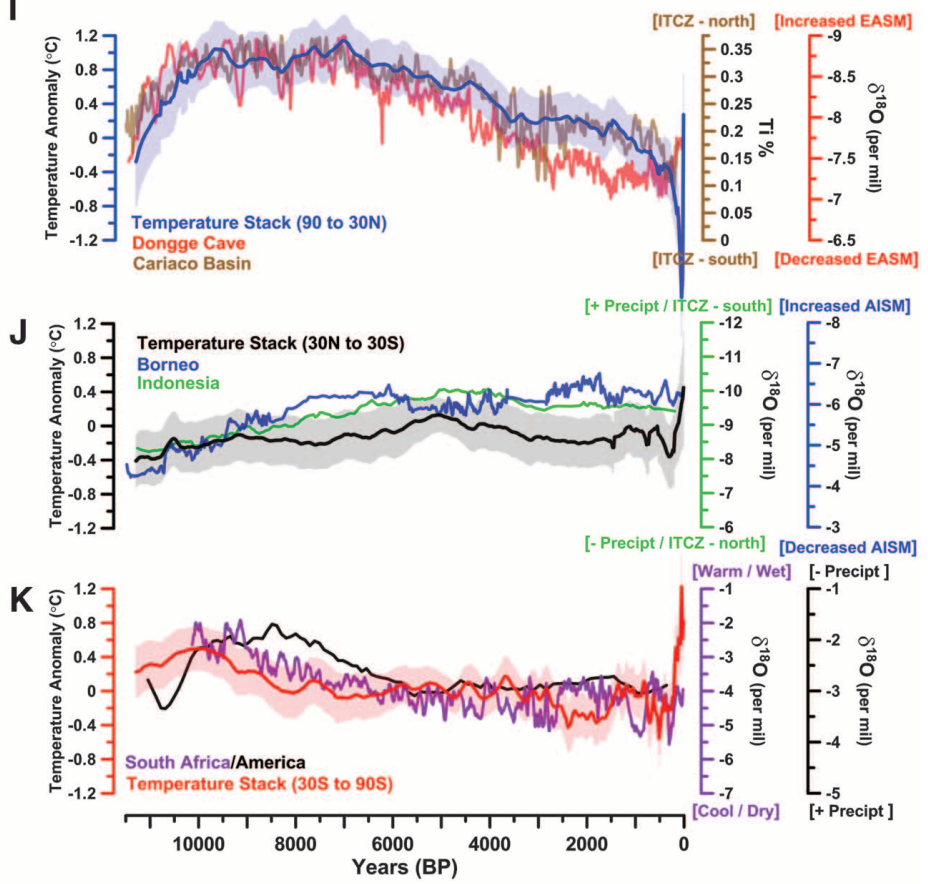

Fig. 2. Holocene climate forcings and paleoclimate records. Contour plots of (A) December, (B) June, and (C) annual mean latitudinal insolation anomalies relative to present for the past 11,500 years (36). (D) Calculated radiative forcing (28) derived from ice-core greenhouse gases $(\mathrm{GHG})\left(\mathrm{CO}_{2}+\mathrm{N}_{2} \mathrm{O}+\mathrm{CH}_{4}\right)$. (E) Total solar irradiance anomalies ( $\triangle \mathrm{TSI}$ ) relative to $1944-1988 \mathrm{CE}$ derived from cosmogenic isotopes (31). ( $\mathbf{F}$ and $\mathbf{G})$ Proxies for the strength of the Atlantic meridional overturning circulation $(37,38)$. (H) Volcanic sulfate flux (in $\mathrm{kg} / \mathrm{km}^{2}$ ) from Antarctica (32) and volcanic sulfate concentration (in parts per billion) from Greenland (33) in 100-year bins. Both records are normalized relative to the volcanic sulfate flux/concentration associated with the Krakatoa eruption. (I to K) Zonal mean temperature reconstructions for $60^{\circ}$ latitude bands from this study compared to speleothem $(14,15,17-20)$ and Ti data (16), which are proxies for precipitation and local temperature. Speleothem data sets were smoothed with a seven-point running mean for clarity. ITCZ, Intertropical Convergence Zone; EASM, East Asian Summer Monsoon; AISM, AustralianIndonesian Summer Monsoon.

speleothem proxies of precipitation and temperature from South Africa (19) and South America (20) that are independent of our reconstruction.

The general pattern of high-latitude cooling in both hemispheres opposed by warming at low latitudes is consistent with local mean annual insolation forcing associated with decreasing orbital obliquity since 9000 years ago (Fig. 2C). The especially pronounced cooling of the Northern Hemisphere extratropics, however, suggests an important role for summer insolation in this region, perhaps through snow-ice albedo and vegetation feedbacks $(21,22)$. Such a mechanism that mediates seasonal insolation is plausible at these latitudes, where the fraction of continental landmasses relative to the ocean is high $\left(\sim 50 \%\right.$ land from $30^{\circ}$ to $90^{\circ} \mathrm{N} ; 25 \%$ land from $30^{\circ} \mathrm{N}$ to $30^{\circ} \mathrm{S} ; 15 \%$ land from $30^{\circ}$ to $90^{\circ} \mathrm{S}$ ).

We cannot fully exclude the possibility of a seasonal proxy bias in our temperature reconstructions (23), but a sensitivity experiment with an intermediate-complexity model (fig. S8) suggests that the effects of such a bias would probably be modest in the global reconstruction. The dominance of the northern signal in our global stack is consistent with Milankovitch theory, in which summer insolation would drive the planet toward eventual future glacial inception in the Northern Hemisphere (24), excluding any anthropogenic influence. Models support our finding of a global mean cooling in response to an obliquity decrease, though of lesser magnitude (25), and also support the idea about the sensitivity of the northern high latitudes to summer insolation (21).

Additional effects probably further influenced the evolution of climate through the Holocene. In the early-to-middle Holocene, the deglaciating Northern Hemisphere ice sheets would have modulated warming of the northern high latitudes relative to peak seasonal insolation $(26,27)$. Radiative forcing by greenhouse gases (primarily $\mathrm{CO}_{2}$ ) rose $0.5 \mathrm{~W} / \mathrm{m}^{2}$ during the mid-to-late Holocene (Fig. 2D), which would be expected to yield $\sim 0.4^{\circ} \mathrm{C}$ warming for a mid-range climate sensitivity (28). Response to such forcing may have been offset by opposing orbital insolation forcing that was greater than greenhouse gas forcing by up to one (annual) to two (seasonal) orders of magnitude over the course of the Holocene (Fig. 2, A to C). North- ward heat transport in the Atlantic basin by the meridional overturning circulation (MOC) may have weakened since the middle Holocene (29), contributing to the strong cooling in the North Atlantic while dampening cooling in the mid-to-high latitude Southern Hemisphere due to the bipolar seesaw (30). Insofar as winter conditions influence the sources and strength of deepwater formation, a weakening MOC may partly reflect the increase in high northern-latitude winter insolation over the Holocene (Fig. 2A). Total solar irradiance reconstructed from cosmogenic isotopes (31) also varied by 0.5 to $1 \mathrm{~W} / \mathrm{m}^{2}$, and volcanic eruptions occurred throughout the duration of the Holocene $(32,33)$, although most of this variance is at higher frequencies than those resolved by our stacked temperature records, and the scaling of both is poorly constrained.

Although our temperature stack does not fully resolve variability at periods shorter than 2000 years, such high-frequency changes would only modestly broaden the statistical distribution of Holocene temperatures (Fig. 3 and fig. S22). Moreover, we suggest that accounting for any spatial or seasonal biases in the stack would tend to reduce its 


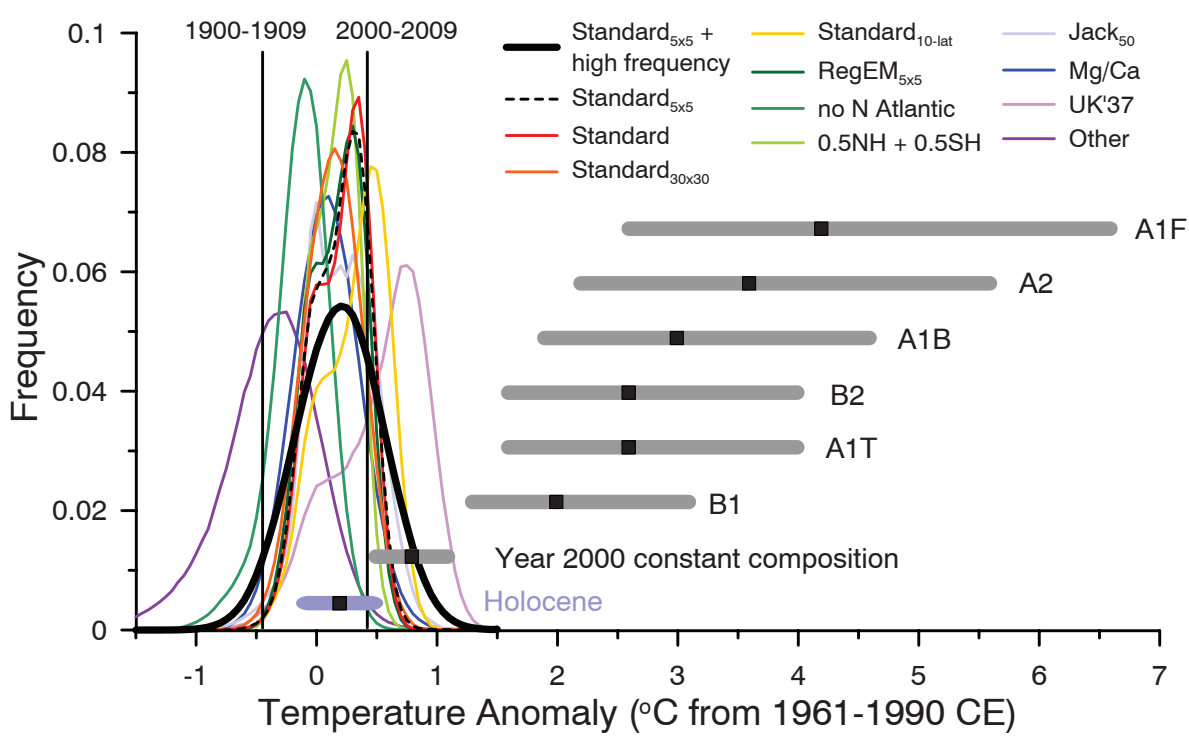

Fig. 3. Holocene temperature distribution compared to modern temperature and future projections. Shown are relative frequency plots of Holocene temperature anomalies in $0.05^{\circ} \mathrm{C}$ bins using multiple data subsets and reconstructions (colored lines), instrumental means for 1900-1909 and 2000-2009 CE (vertical black lines), 2100 CE projections based on various emissions scenarios (35) (black squares and gray bars give the best estimate and $66 \%$ confidence interval), and the Holocene median and $66 \%$ range from Standard ${ }_{5 \times 5}+$ high-frequency stack (black square and blue bar). Projections in (35) were referenced to 1980-1999 CE, whereas we reference them to 1961-1990 CE here. Data sets are divided by proxy type: UK'37, Mg/Ca, and the remainder (Other); method: arithmetic mean (Standard) and RegEM; weighting: equal Northern and Southern Hemisphere weighting $(0.5 \mathrm{NH}+0.5 \mathrm{SH}), 5^{\circ} \times 5^{\circ}$ grid, and $30^{\circ} \times 30^{\circ}$ grid; exclusion of data sets: no North Atlantic and Jack $_{50}$; and high-frequency addition: red noise with the same power spectrum as Mann et al. (2) added to the global stack (supplementary materials).

variability because of the cancellation of noise in a large-scale mean and the opposing nature of seasonal insolation forcing over the Holocene, causing the Holocene temperature distribution to contract.

Our results indicate that global mean temperature for the decade 2000-2009 (34) has not yet exceeded the warmest temperatures of the early Holocene (5000 to $10,000 \mathrm{yr}$ B.P.). These temperatures are, however, warmer than $82 \%$ of the Holocene distribution as represented by the Standard ${ }_{5 \times 5}$ stack, or $72 \%$ after making plausible corrections for inherent smoothing of the high frequencies in the stack ( 6 ) (Fig. 3). In contrast, the decadal mean global temperature of the early 20 th century (1900-1909) was cooler than $>95 \%$ of the Holocene distribution under both the Standard $_{5 \times 5}$ and high-frequency corrected scenarios. Global temperature, therefore, has risen from near the coldest to the warmest levels of the Holocene within the past century, reversing the long-term cooling trend that began $\sim 5000$ yr B.P. Climate models project that temperatures are likely to exceed the full distribution of Holocene warmth by 2100 for all versions of the temperature stack (35) (Fig. 3), regardless of the greenhouse gas emission scenario considered (excluding the year 2000 constant composition scenario, which has already been exceeded). By 2100, global average temperatures will probably be 5 to 12 standard deviations above the Holocene temperature mean for the A1B scenario (35) based on our Standard $5 \times 5$ plus high-frequency addition stack (Fig. 3).
Strategies to better resolve the full range of global temperature variability during the Holocene, particularly with regard to decadal to centennial time scales, will require better chronologic constraints through increased dating control. Higherresolution sampling and improvements in proxy calibration also play an important role, but our analysis (fig. S18) suggests that improvements in chronology are most important. Better constraints on regional patterns will require more data sets from terrestrial archives and both marine and terrestrial records representing the mid-latitudes of the Southern Hemisphere and central Pacific.

\section{References and Notes}

1. E. Jansen et al., in Climate Change 2007: The Physical Science Basis. Contribution of Working Group I to the Fourth Assessment Report of the Intergovernmental Panel on Climate Change, S. Solomon et al., Eds. (Cambridge Univ. Press, Cambridge, 2007), pp. 433-497.

2. M. E. Mann et al., Proc. Natl. Acad. Sci. U.S.A. 105, 13252 (2008)

3. A. Moberg, D. M. Sonechkin, K. Holmgren, N. M. Datsenko, W. Karlén, Nature 433, 613 (2005). 4. H. Wanner et al., Quat. Sci. Rev. 27, 1791 (2008).

5. The majority of the data sets can be found at NOAA National Climate Data Center (www.ncdc.noaa.gov/paleo/paleo.html) and the PANGAEA data repository (www.pangaea.de/). Sources for all data sets are available online (6).

6. Materials, methods, and supporting data are available as supplementary materials on Science Online.

7. J. Esper, E. R. Cook, F. H. Schweingruber, Science 295, 2250 (2002).

8. C. M. Ammann, E. R. Wahl, Clim. Change 85, 71 (2007).
9. ]. Esper, D. C. Frank, R. J. S. Wilson, EOS $85,113,120$ (2004).

10. J. Esper et al., Nat. Clim. Change 10.1038/nclimate1589 (2012).

11. T. Schneider, J. Clim. 14, 853 (2001).

12. E. R. Wahl, C. M. Ammann, Clim. Change 85, 33 (2007)

13. E. R. Wahl, D. M. Ritson, C. M. Ammann, Science 312, 529, author reply 529 (2006).

14. C. A. Dykoski et al., Earth Planet. Sci. Lett. 233, 71 (2005).

15. Y. Wang et al., Science 308, 854 (2005).

16. G. H. Haug, K. A. Hughen, D. M. Sigman, L. C. Peterson, U. Röhl, Science 293, 1304 (2001).

17. ]. W. Partin, K. M. Cobb, J. F. Adkins, B. Clark D. P. Fernandez, Nature 449, 452 (2007).

18. M. L. Griffiths et al., Nat. Geosci. 2, 636 (2009).

19. K. Holmgren et al., Quat. Sci. Rev. 22, 2311 (2003).

20. F. W. Cruz Jr. et al., Nature 434, 63 (2005).

21. H. Renssen et al., Clim. Dyn. 24, 23 (2005).

22. A. Ganopolski, C. Kubatzki, M. Claussen, V. Brovkin, V. Petoukhov, Science 280, 1916 (1998).

23. G. Leduc, R. Schneider, ].-H. Kim, G. Lohmann, Quat. Sci. Rev. 29, 989 (2010).

24. P. C. Tzedakis, J. E. T. Channell, D. A. Hodell, H. F. Kleiven, L. C. Skinner, Nat. Geosci. 10.1038/ngeo1358 (2012).

25. D. F. Mantsis, A. C. Clement, A. J. Broccoli, M. P. Erb, J. Clim. 24, 2830 (2011).

26. D. S. Kaufman et al., Quat. Sci. Rev. 23, 529 (2004).

27. F. C. Ljungqvist, Geografia 116, 91 (2011)

28. V. Ramaswamy et al., Eds., Radiative Forcing of Climate Change. Climate Change 2001: The Scientific Basis. Contribution of Working Group I to the Third Assessment Report of the Intergovernmental Panel on Climate Change (Cambridge Univ. Press, New York, 2001)

29. B. A. A. Hoogakker et al., Paleoceanography 26, PA4214 (2011).

30. W. S. Broecker, Paleoceanography 13, 119 (1998).

31. F. Steinhilber et al., Proc. Natl. Acad. Sci. U.S.A. 109, 5967 (2012).

32. E. Castellano et al., J. Geophys. Res. 110, D06114 (2005).

33. G. A. Zielinski, P. A. Mayewski, L. D. Meeker, S. Whitlow M. S. Twickler, Quat. Res. 45, 109 (1996).

34. P. Brohan, J. J. Kennedy, I. Harris, S. F. B. Tett, P. D. Jones, J. Geophys. Res. 111, D12106 (2006).

35. G. A. Meehl et al., in Climate Change 2007: The Physical Science Basis. Contribution of Working Group I to the Fourth Assessment Report of the Intergovernmental Panel on Climate Change, S. Solomon et al., Eds. (Cambridge Univ. Press, Cambridge, 2007), pp. 747-845.

36. S. Huang, Geophys. Res. Lett. 31, L13205 (2004).

37. A. Berger, M.-F. Loutre, Quat. Sci. Rev. 10, 297 (1991).

38. J. F. McManus, R. Francois, ].-M. Gherardi, L. D. Keigwin, S. Brown-Leger, Nature 428, 834 (2004).

Acknowledgments: We thank ]. Alder, T. Bauska, E. Brook, C. Buizert, V. Ersek, S. Hostetler, P. Huybers, N. Pisias, J. Rosen, G. Schmidt, A. Schmittner, M. Tingley, and our reviewers for invaluable insight and helpful discussion. The data sets provided by T. Barrows, J.-H. Kim, Y. Kubota, I. Larocque, G. Leduc, M. McGlone, T. Rodrigues, C. Rühlemann, ]. Sachs, R. Schneider, H. Seppä, J. Tierney, M. Yamamoto, B. Vinther, and C. Waelbrock, as well as the data sets compiled from the National Oceanic and Atmospheric Administration Climate Data Center and PANGAEA databases, made this research possible. Funding for this work was provided by the NSF Paleoclimate Program for the Paleovar Project.

\section{Supplementary Materials}

www.sciencemag.org/cgi/content/full/339/6124/1198/DC1 Supplementary Text

Figs. S1 to S26

References

27 July 2012; accepted 4 January 2013

$10.1126 /$ science. 1228026 